Pacific Journal of Mathematics

ON A HOMOTOPY CONVERSE TO THE LEFSCHETZ FIXED (R) 


\title{
ON A HOMOTOPY CONVERSE TO THE LEFSCHETZ FIXED POINT THEOREM
}

\author{
ROBERT F. BROWN
}

\begin{abstract}
Let $\alpha$ be a homotopy class of maps of $X$, a connected compact metric ANR, into itself and let $L_{\alpha}$ denote the Lefschetz number of $\alpha$. A converse to the Lefschetz fixed point theorem is: if $L_{\alpha}=0$ then $\alpha$ contains a fixed point free map. The converse is true if $X$ is a compact connected simply-connected topological $n$-manifold (Fadell) or if $X$ is a compact connected topological $n$-manifold, with or without boundary, and $\alpha$ contains the identity map (Brown-Fadell). Let $\mu(\alpha)$ denote the fixed point class invariant of $\alpha$, then every map in $\alpha$ has at least $\mu(\alpha)$ fixed points. The purpose of this paper is to generalize the preceding results by proving that if $X$ is a compact connected topological $n$-manifold, $n \geqq 3$, with or without boundary, then there is a map in $\alpha$ which has exactly $\mu(\alpha)$ fixed points. It follows that the converse to the Lefschetz theorem will hold whenever $\alpha$ contains a map all of whose fixed points are in a single fixed point class.
\end{abstract}

Let $X$ be a topological space and let $f: X \rightarrow X$ be a map. If $x, x^{\prime} \in X$ are fixed points of $f$, then $x$ and $x^{\prime}$ are in the same fixed point class [7], [9] of $f$ if there is a path $w: I \rightarrow X(I=[0,1])$ homotopic to the path $f w$ by a homotopy keeping $x$ and $x^{\prime}$ fixed, i.e., there exists a map $H: I \times I \rightarrow X$ such that $H(s, 0)=w(s), H(s, 1)=$ $f(w(s))$, for all $s \in I$, and $H(0, t)=x, H(1, t)=x^{\prime}$, for all $t \in I$.

In order to state our theorem, we will need the results of Browder's extensive research on fixed point classes and the fixed point index [1], [2]. For the reader's convenience, we will summarize those results which we require. Let $X$ be a connected compact metric ANR. Let $f: X \rightarrow X$ be a map and let $\alpha$ denote the homotopy class of maps containing $f$. The fixed points of $f$ belong to a finite number of fixed point classes $\mathfrak{F}_{1}, \cdots, \mathfrak{F}_{r}$. There is a set of mutually disjoint open sets $\mathbb{B}_{1}, \cdots, \mathscr{S}_{r}$ of $X$ such that $\mathfrak{\mho}_{j} \subset \mathbb{B}_{j}, j=1, \cdots, r$. The fixed point index $i\left(f, \mathbb{S}_{j}\right)$ of $f$ on $\mathbb{B}_{j}$ is well-defined and independent of the choice of $\mathbb{B}_{j}$. Call this integer the index of the fixed point class $\widetilde{F}_{j}$ and denote it by $i\left(\mathfrak{\mho}_{j}\right)$. Let $\mu(f)$ denote the number of fixed point classes $\mathfrak{\mho}_{j}$ of $f$ such that $i\left(\mathfrak{\mho}_{j}\right) \neq 0$. If $g \in \alpha$, then $\mu(g)=\mu(f)$ so we may replace $\mu(f)$ by $\mu(\alpha)$. Every map in $\alpha$ has at least $\mu(\alpha)$ fixed points.

THEOREM 1. Let $M$ be a compact connected topological n-manifold,

Received December 10, 1964. This research was supported in part by the Air Force Office of Scientific Research. 
$n \geqq 3$, with or without boundary, and let $\alpha$ be a homotopy class of maps of $M$ into itself. There is a map $f \in \alpha$ which has exactly $\mu(\alpha)$ fixed points.

In the case of triangulated manifolds, Theorem 1 is a consequence of Theorem 3 of [9]. (See [13] for the announcement of a different extension of Wecken's theorem to topological manifolds.) The restriction on the dimension of the manifold in Theorem 1 is necessary; a two-dimensional counter-example is known [14].

If all the fixed points of a map $g \in \alpha$ are in the same fixed point class $\mathfrak{F}$, then we can take $\mathbb{B}=M$ and $i(\mathfrak{F})=i(g, M)=L_{g}=L_{\alpha}[2$, Theorem 4]. Therefore, we have the following homotopy converse to the Lefschetz fixed point theorem.

COROLLARY. Let $M$ be a compact connected topological n-manifold, $n \geqq 3$, with or without boundary, and let $\alpha$ be a homotopy class of maps on $M$ which contains a map all of whose fixed points lie in a single fixed point class. If $L_{\alpha}=0$, then $\alpha$ contains a fixed point free map.

It is clear that for manifolds of dimension at least three, the converses to the Lefschetz theorem obtained by Fadell [5] and by Brown and Fadell [4] stated above are immediate consequences of the corollary.

Although the Lefschetz fixed point theorem itself holds for very general categories of spaces [2], [6], the converse fails to be true even for finite polyhedra, e.g., for the class of the identity map on $S^{2} \vee S^{1} \vee S^{1}$ (Y. H. Clifton).

2. Fixed points of maps on manifolds with boundary. The results of this section are generalizations of theorems of Weier [12]. (A closely related development is given in [11].).

Theorem 2. Let $M$ be a compact connected topological manifold with boundary and let $f: M \rightarrow M$ be a map, then there exists a map $f^{\prime}: M \rightarrow M$ homotopic to $f$ such that $f^{\prime}$ has a finite number of fixed points; none of which lie on the boundary of $M$.

Proof. If we identify two copies of $M$ by the identity homeomorphism restricted to the boundary $B$ of $M$, we obtain a compact connected manifold without boundary called the double of $M$ and denoted by $2 M$. Denote one of the copies of $M$ in $2 M$ by $M_{1}$ and consider $f$ to be a map on $M_{1}$. It follows immediately from [3, Theorem 2] that there is a homeomorphism $h$ of $B \times I$ into $M_{1}$ such 
that $h(b, 0)=b \in B$. Define a family of maps $r^{t}: M_{1} \rightarrow M_{1}, t \in I$, by letting $r^{t}(x)=x$ for all $x \in\left[M_{1}-h(B \times I)\right]$ and all $t \in I$ and for $h(b, s) \in h(B \times I)$, let $r^{t}(h(b, s))=h(b,(1-s) t+s)$. The map $f$ induces $F: 2 M \rightarrow M_{1}$ in the obvious way so that $F(x)=f(x)$ for all $x \in M_{1}$. Consider $g=r^{1} F: 2 M \rightarrow M_{1}$, then $g$ is homotopic to $F, g \mid M_{1}$ ( $g$ restricted to $\left.M_{1}\right)$ is homotopic to $f$, and $g\left(M_{1}\right) \subseteq\left[M_{1}-h(B \times[0,1))\right]$. Let $\varepsilon>0$ denote the distance from $B$ to $h(B \times\{1\})$. By Theorem 1 of [12], there is a homotopy $g^{t}: 2 M \rightarrow 2 M, t \in I$, such that $g^{0}=g, \rho\left(g^{t}(x), g(x)\right)<\varepsilon$ for all $t \in I$ and $x \in 2 M$ ( $\rho$ is the metric of $2 M$ ) and $g^{1}$ has at most a finite number of fixed points. By the definition of $\varepsilon$, it is clear that $f^{\prime}=g^{1} \mid M_{1}: M_{1} \rightarrow M_{1}$ is homotopic to $f$ and $f^{\prime}\left(M_{1}\right) \subseteq M_{1}-B$ so $f^{\prime}$ has no fixed points on $B$.

REMARK. Suppose $x, x^{\prime} \in M$ are fixed points of $f: M \rightarrow M$ which are in the same fixed point class of $f$ by means of a path $w$, that is, $w$ is a path in $M$ from $x$ to $x^{\prime}$ which is homotopic to $f w$ by a homotopy which keeps $x$ and $x^{\prime}$ fixed. Let $w^{\prime}: I \rightarrow M$ be a path from $x$ to $x^{\prime}$ which is homotopic to $w$ by a homotopy which keeps $x$ and $x^{\prime}$ fixed, then $x$ and $x^{\prime}$ are in the same class of $f$ by means of $w^{\prime}$.

THEOREM 3. Let $M$ be a compact connected topological n-manifold, $n \geqq 3$, with boundary $B$ and let $g: M \rightarrow M$ be a map with a finite number of fixed points, none of which lie on $B$. If $x_{0}$ and $x_{1}$ are fixed points of $g$ in the same fixed point class, then there exists an open set $W \subseteq M$, containing $x_{0}$ and $x_{1}$ but no other fixed point of $g$, and a map $g^{\prime}: M \rightarrow M$ such that $g^{\prime}$ is homotopic to $g, g^{\prime}(x)=g(x)$ for all $x \in M-W$, and $x_{0}$ is the only fixed point of $g^{\prime}$ in $W$.

Proof. We first show that $x_{0}$ and $x_{1}$ belong to the same fixed point class of $g$ by means of a path $w^{\prime}: I \rightarrow M$ such that $w^{\prime}(I) \cap B=$ $\varnothing$. By hypothesis, $x_{0}$ and $x_{1}$ are in the same class by means of a path $w^{\prime \prime}$. By Theorem 2 of [3], there is a neighborhood $U$ of $B$ in $M$ and a homeomorphism $h: B \times[0,1) \rightarrow U$ (onto) such that $h(b, 0)=$ $b \in B$. Since neither $x_{0}$ nor $x_{1}$ is in $B$, we can construct $U$ so that it does not contain these points. Define the path $w^{\prime}$ by

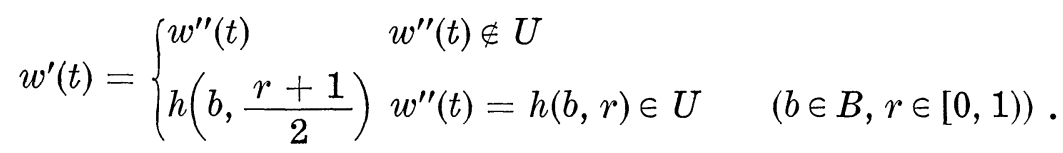

Define $K: I \times I \rightarrow M$ by

$$
K(t, s)= \begin{cases}w^{\prime \prime}(t) & w^{\prime \prime}(t) \notin U, \\ h\left(b,\left[\frac{1-r}{2}\right] s+r\right) & w^{\prime \prime}(t)=h(b, r) \in U,\end{cases}
$$


then $K$ is a homotopy connecting $w^{\prime \prime}$ and $w^{\prime}$ keeping $x_{0}$ and $x_{1}$ fixed, so by the remark, $w^{\prime}$ is the required path. Now suppose that for some fixed point $x_{2}$ of $g$ we have $w^{\prime-1}\left(x_{2}\right)=J \neq \varnothing$. Let $N$ be a Euclidean neighborhood of $x_{2}$ containing no other fixed point of $g$ and let $a: N \rightarrow R^{n}$ be a homeomorphism taking $x_{2}$ to the origin. Let $\bar{A}$ be the closed unit ball in $R^{n}$ centered at the origin and let $\bar{V}=a^{-1}(\bar{A})$. Let $\left\{C_{\gamma}\right\}$ denote the components of $w^{\prime-1}(\bar{V}) \subset I$, then by the continuity of $w^{\prime}$, there are only a finite number of such components $\left\{C_{i}\right\}_{i=1}^{m}$ with the property $C_{i} \cap J \neq \varnothing$. Note that $C_{i}=\left[c_{i}, d_{i}\right] \subset(0,1)$ for $i=1, \cdots, m$ and let $\zeta_{1}:\left[c_{1}, d_{1}\right] \rightarrow N-V$ such that $\zeta_{1}\left(c_{1}\right)=w^{\prime}\left(c_{1}\right), \zeta_{1}\left(d_{1}\right)=w^{\prime}\left(d_{1}\right)$, then the path $w_{1}^{\prime}$ defined by

$$
w_{1}^{\prime}(t)= \begin{cases}w^{\prime}(t) & t \in I-\left(c_{1}, d_{1}\right) \\ \zeta_{1}(t) & t \in\left[c_{1}, d_{1}\right]\end{cases}
$$

is homotopic to $w^{\prime}$ by a homotopy which is constant outside of $N$ and so, in particular, keeps $x_{0}$ and $x_{1}$ fixed. Thus, by the remark, $x_{0}$ and $x_{1}$ are in the same fixed point class of $g$ by means of $w_{1}^{\prime}$. Repeating this construction a finite number of times, we obtain a path $w: I \rightarrow M$ such that $x_{0}$ and $x_{1}$ are in the same fixed point class of $g$ by means of $w, w(I) \cap B=\varnothing$, and $w$ intersects no other fixed point of $g$. Hence there exists an open set $W$ in $M-B$ containing $w$ and disjoint from all fixed points of $g$ except $x_{0}$ and $x_{1}$. We can now apply the proof of Theorem 5 of [12] to $g, W, x_{0}$ the $x_{1}$ without any changes whatsoever to obtain the required map $g^{\prime}: M \rightarrow M$.

3. Proof of Theorem 1. By Theorem 2, there is a map $f^{\prime} \in \alpha$ with a finite number of fixed points, none of which lie on the boundary $B$ of $M$. Applying Theorem 3 to $f^{\prime}$ a finite number of times, we obtain a map $g \in \alpha$ no two of whose fixed points are in the same fixed point class of $g$. Denote the fixed points of $g$ by $x_{1}, \cdots, x_{r}(\varepsilon M-B)$, then there exist Euclidean neighborhoods $U_{1}, \cdots, U_{r}$ such that $x_{j} \in U_{j}$, $j=1, \cdots, r, \bar{U}_{j} \cap \bar{U}_{k}=\varnothing$ for $j \neq k$, and $i\left(x_{j}, U_{j}\right)=i\left(\mathfrak{F}_{j}\right)$ where $\mathfrak{\mho}_{j}$ denotes a fixed point class of $g$. By a result quoted above $(\S 1), i\left(\widetilde{\mho}_{j}\right) \neq 0$ for exactly $\mu(\alpha)$ of the classes $\widetilde{F}_{j}$. Let $x_{j}$ be a fixed point of $g$ such that $i\left(\mathfrak{\mho}_{j}\right)=0$. There is a homeomorphism $h: U_{j} \rightarrow R^{n}$ (onto) taking $x_{j}$ to the origin. Let $\bar{A}$ be the closed unit ball in $R^{n}$ centered at the origin and let $\bar{V}=h^{-1}(\bar{A})$. We may obtain a finite triangulation of $\bar{V}$ of mesh small enough so that if $P$ is the closed star of $x_{j}$ then $g(P) \subset V$. A slight modification of the proof of Proposition 1.1 of [4] permits us to identify O'Neill's index on $U_{j}$ [8] with the index we have been using in this paper. Therefore, the index of $g$ on $U_{j}$ as defined in [8] is zero and by Corollary 5.3 of that paper, there is a map $g^{\prime}: M \rightarrow M$ such that $g^{\prime}$ has no fixed point on $U_{j}$ and $g^{\prime}$ is suf- 
ficiently close to $g$ so that $g^{\prime}(P) \subset U_{j}$. Furthermore, from the proof of Theorem 5.2 of [8], it follows that, for $x \in M-P, g^{\prime}(x)=g(x)$. Thus $g^{\prime} \in \alpha$ and $g^{\prime}$ has the same fixed points as $g$ except for $x_{j}$. If we repeat this construction for each fixed point $x_{k}$ of $g$ such that $i\left(\mathfrak{F}_{k}\right)=0$, we obtain in a finite number of steps a map $f \in \alpha$ with exactly $\mu(\alpha)$ fixed points.

\section{REFERENCES}

1. F. Browder, The topological fixed point theory and its application in functional analysis, Doctoral Dissertation, Princeton University, 1948.

2. - On the fixed point index for continuous mappings of locally connected spaces, Summa Brasil. Math. 4 (1960), 253-293.

3. M. Brown, Locally flat embeddings of topological manifolds, Topology of 3-manifolds and related topics, Prentice-Hall, (1962).

4. R. Brown and E. Fadell, Non-singular path fields on compact topological manifolds, Proc. Amer. Math. Soc. 16 (1965), 1342-1349.

5. E. Fadell, On a coincidence theorem of F. B. Fuller, Pacific J. Math., (to appear).

6. R. Knill, On the Lefschetz coincidence point formula, Doctoral Dissertation, U. of Notre Dame, 1964.

7. J. Nielson, Untersuchungen zur Topologie der geschlossenen zweiseitigen Fläche, I, Acta Math. 50 (1927), 189-358.

8. B. O'Neill, Essential sets and fixed points, Amer. J. Math. 75 (1953), 497-509.

9. F. Wecken, Fixpunktklassen, I, Math. Ann. 117 (1940-1), 659-671.

10. - Fixpunktklassen, III, Math. Ann. 118 (1941-3), 544-577.

11. J. Weier, Die Randsingularitäten von offener Mengen in sich, Math. Ann. 130 (1955), 196-201.

12. - Fixpunkttheorie in topologische Mannigfaltigkeiten, Math. Z. 59 (1953), 171-190.

13. - Sur les class essentielles des deux représentations, C. R. Acad. Sci. Paris 239 (1954), 337-339.

14. - Ueber Probleme aus der Topologie der Ebene und der Flächen, Math. Japon 4 (1956), 101-105.

University of CALifornia, Los ANgeles 



\title{
PACIFIC JOURNAL OF MATHEMATICS
}

\author{
EDITORS
}

\section{H. SAMELSON}

Stanford University

Stanford, California

R. M. Blumenthal

University of Washington

Seattle, Washington 98105

\section{*J. DugundJI}

University of Southern California Los Angeles, California 90007

\section{RichaRd ARENS}

University of California

Los Angeles, California 90024

\section{ASSOCIATE EDITORS}
E. F. BECKENBACH
B. H. NEUManN
F. WOLF
K. YOSIDA

\section{SUPPORTING INSTITUTIONS}

\author{
UNIVERSITY OF BRITISH COLUMBIA \\ CALIFORNIA INSTITUTE OF TECHNOLOGY \\ UNIVERSITY OF CALIFORNIA \\ MONTANA STATE UNIVERSITY \\ UNIVERSITY OF NEVADA \\ NEW MEXICO STATE UNIVERSITY \\ OREGON STATE UNIVERSITY \\ UNIVERSITY OF OREGON \\ OSAKA UNIVERSITY \\ UNIVERSITY OF SOUTHERN CALIFORNIA
}

\author{
STANFORD UNIVERSITY \\ UNIVERSITY OF TOKYO \\ UNIVERSITY OF UTAH \\ WASHINGTON STATE UNIVERSITY \\ UNIVERSITY OF WASHINGTON \\ AMERICAN MATHEMATICAL SOCIETY \\ CHEVRON RESEARCH CORPORATION \\ TRW SYSTEMS \\ NAVAL ORDNANCE TEST STATION
}

\footnotetext{
Mathematical papers intended for publication in the Pacific Journal of Mathematics should be typewritten (double spaced). The first paragraph or two must be capable of being used separately as a synopsis of the entire paper. It should not contain references to the bibliography. Manuscripts may be sent to any one of the four editors. All other communications to the editors should be addressed to the managing editor, Richard Arens at the University of California, Los Angeles, California 90024 .

50 reprints per author of each article are furnished free of charge; additional copies may be obtained at cost in multiples of 50 .
}

The Pacific Journal of Mathematics is published monthly. Effective with Volume 16 the price per volume (3 numbers) is $\$ 8.00$; single issues, $\$ 3.00$. Special price for current issues to individual faculty members of supporting institutions and to individual members of the American Mathematical Society: $\$ 4.00$ per volume; single issues $\$ 1.50$. Back numbers are available.

Subscriptions, orders for back numbers, and changes of address should be sent to Pacific Journal of Mathematics, 103 Highland Boulevard, Berkeley 8, California.

Printed at Kokusai Bunken Insatsusha (International Academic Printing Co., Ltd.), No. 6, 2-chome, Fujimi-cho, Chiyoda-ku, Tokyo, Japan.

PUBLISHED BY PACIFIC JOURNAL OF MATHEMATICS, A NON-PROFIT CORPORATION

The Supporting Institutions listed above contribute to the cost of publication of this Journal, but they are not owners or publishers and have no responsibility for its content or policies.

* Paul A. White, Acting Editor until J. Dugundji returns. 


\section{Pacific Journal of Mathematics}

\section{Vol. 17, No. $3 \quad$ March, 1966}

Tsuyoshi Andô, Contractive projections in $L_{p}$ spaces ............... 391

Robert F. Brown, On a homotopy converse to the Lefschetz fixed point theorem ............................................... 407

Richard Albert Cleveland and Sandra Cleveland, On the multiplicative extension property................................ 413

Harold H. Johnson, An algebraic approach to exterior differential systems..................................... 423

Alan Cecil Lazer, The behavior of solutions of the differential equation

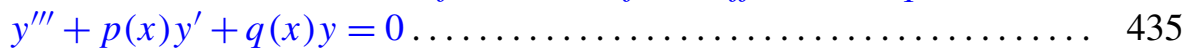

Judy Parr, Cohomology of cyclic groups of prime square order ......... 467

Donald Steven Passman, Groups whose irreducible representations have

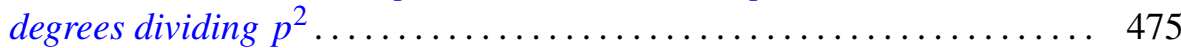

Ralph Tyrrell Rockafellar, Characterization of the subdifferentials of convex functions ........................................... 497

Donald Erik Sarason, Invariant subspaces and unstarred operator algebras...................................... 511

Donald Erik Sarason, Weak-star generators of $H^{\infty} \ldots \ldots \ldots \ldots \ldots \ldots . \ldots . \ldots$

Boris M. Schein, Homomorphisms and subdirect decompositions of semi-groups

Daniel Francis Shea, Jr., Functions analytic in a finite disk and having asymptotically prescribed characteristic

Zvi Ziegler, Generalized convexity cones 